Mirai. Estudios Japoneses

ISSN-e: 1988-2378

http://dx.doi.org/10.5209/MIRA.57108

\title{
El Japón que nunca publicó el National Geographic. Hallazgo de nuevas fotografías de Eliza Scidmore
}

\author{
Ramón Vega Piniella ${ }^{1}$
}

Resumen: Eliza Ruhamah Scidmore (1856, Clinton, Iowa -1928, Génova, Suiza) fue una geógrafa, fotógrafa, activista, coleccionista, escritora y periodista estadounidense. Sus logros en todos estos campos atrajeron el interés de la National Geographic Society, donde se confirmó como una auténtica pionera.

Gran interesada en Japón, entre 1885 y 1928, tuvo incontables estancias en el archipiélago nipón, convirtiéndose en un referente internacional sobre el país, mostrando su realidad a millones de lectores. También realizó esta difusión publicando varios libros de viajes y novelas, acompañados por sus fotografías, convirtiéndose además en la principal promotora de la icónica imagen del cerezo japonés en flor.

A pesar de su prolija obra, muchas de sus fotografías de Japón tuvieron una difusión limitada. Por suerte, tras contrastar los archivos del fondo fotográfico de National Geographic en Washington con los fondos de la familia Galé en el Muséu del Pueblu d'Asturies, localizamos una serie de albúminas coloreadas de Japón realizadas por Eliza Scidmore, que se habían dado por perdidas.

Palabras clave: Fotografía; Japón; Eliza Ruhamah Scidmore; National Geographic; Jesús Teodoro Galé.

\section{[en] The Japan that National Geographic never published. Discovery of new photographs by Eliza Scidmore}

\begin{abstract}
Eliza Ruhamah Scidmore (b.1856, U.S.A. - d.1928, Switzerland) was an American geographer, photographer, activist, collector, writer and journalist. Her achievements attracted the interest of the National Geographic Society, where she confirmed herself as a pioneer in these fields.

Greatly interested in Japan, she made countless trips and stayed in the Japanese archipelago between 1885 and 1928, becoming an international point of reference on the situation of the country, showing it to millions of readers subscribed to the National Geographic Magazine. Additionally, Scidmore also published several travel books and novels. All these materials were accompanied by extensive photographs taken during her stay in Japan. With her work she became one of the main promoters of the iconic image of Japanese cherry blossoms.

Despite the extensiveness of Scidmore's work, the dissemination of most of her photographs capturing Japan was limited. Fortunately, after contrasting countless files in the National Geographic Society Archive in Washington, with funds from the Gale family in the Muséu del Pueblu d'Asturies, we were able to locate a series of coloured albumen prints by Eliza Scidmore representing Japan, which were thought to be lost.

Keywords: Photography; Japan; Eliza Ruhamah Scidmore; National Geographic; Jesús Teodoro Galé.
\end{abstract}

Sumario. 1. Escribiendo sobre Japón. 2. Scidmore la National Geographic. 3. Fotografías. 3.1. Nuevas fotografías de Eliza Scidmore. Conclusiones.

Cómo citar: Vega Piniella, R. (2017). El Japón que nunca publicó el National Geographic. Hallazgo de nuevas fotografías de Eliza Scidmore (2017), en Mirai. Estudios Japoneses 1, 2017, 143-155.

Universidad de Oviedo.

ramonvegap@gmail.com 


\section{Escribiendo sobre Japón}

La primera publicación de Eliza Ruhamah Scidmore ${ }^{2}$ (1856-1928) vinculada al arte y cultura japonesas fue portada del National Republican, mientras cubría como corresponsal especial la Exposición Universal de Filadelfia de $1876^{3}$. Ese acontecimiento la acercó aún más a la cultura japonesa, ya que pudo entrevistarse con varios comisionados y artesanos, impresionando a la joven Eliza tanto por el resultado de su trabajo como por su manera de hacerlo.

El otro hito indispensable en su relación con Japón fue el destino de su hermano George Hawthorne Scidmore (1854-1922), diplomático y abogado estadounidense. En 1885 es destinado a la embajada estadounidense Japón, lo que motivó que tanto Scidmore como su madre le acompañaran en su nueva etapa asiática. Por entonces, ya era la primera geógrafa americana, a lo que se sumaban las posiciones de su familia, inicialmente de su madre ${ }^{4}$. Mientras, la posición de su hermano en Japón le permitió acceder a recepciones y localizaciones como parte de la embajada que de otra manera se le habrían negado.

Desde entonces, sus viajes al archipiélago nipón eran tan relevantes que su salida era publicada en las notas de sociedad por medios de todo el país ${ }^{5}$. Continuó publicando artículos sobre sus viajes para rotativos como el Washington Post, el New York Times y Chicago Tribune. Un total de más de trescientos artículos a los que se añaden ocho libros de viajes y varias novelas, en su mayor parte dedicados a Asia. En todos ellos encontramos un constante ánimo explícito para la visita del país, su cultura y su naturaleza. Para 1902, ya había visitado Japón al menos media docena de veces, y no dejó de hacerlo hasta su fallecimiento en 1928.

Antes de comenzar a promover el turismo en Japón, dedicó su interés a los territorios inexplorados de EEUU con Alaska, Its Southern Coast and the Sitkan Archipelago $(1885)^{6}$. En él trata de dirigir las miras de los viajeros americanos hacia este territorio patrio, en lugar de los destinos más habituales como París, Roma o Suiza 7 . Su primera obra monográfica sobre el turismo y Japón fue Jinrikisha Days in Japan (1891). Se trata de una guía con ilustraciones basadas en sus propias fotografías, que sirve como acercamiento ligero, pero serio a la cultura japonesa. Al año siguiente amplió los materiales en Westward to the Far East: A Guide to the Principal Cities of China and Japan. La obra es una auténtica alabanza a la cultura japonesa, comisionada por la compañía Canadian Pacific con el fin de atraer turistas e inversores. La guía fue un auténtico éxito, con reediciones constantes hasta $1905^{8}$. Sentó las ba-

2 Esta investigación ha sido llevada a cabo gracias a la subvención de la beca de Formación del Profesorado Universitario (FPU) y del Banco Santander a través de la Universidad de Oviedo, con la colaboración y cesión de imágenes por la National Geographic Society.

3 Scidmore, Eliza R. (1876): "World's Festival. Graphic Description on Interesting Scenes and Incidents". En: The National Republican. Vol. XVL, No 144 May 12. Washington D.C., p.1.

4 Entre los contactos de su madre "Liz" se contaban varios presidentes, incluido Abraham Lincoln (1809-1865) y su entorno.

5 Anónimo (1920): "Social Notes", The New York Times, Nueva York, 9/03/1920. http://query.nytimes.com/mem/ archive-free/pdf?res=9F02E7DA163AEE32A2575AC0A9659C946195D6CF [27/03/2017]

6 Scidmore, Eliza R. (1885): Alaska its southern coast and the Sitkan Archipielago. Boston: D. Lothorp and Company, p. iii. Se trata de una compilación de artículos publicados en el St-Louis Globe Democrat y en el New York Times entre 1883 y 1884, ampliados con documentación. Sus temáticas varían desde los artículos centrados en la geografía a los estudios etnográficos de los asentamientos indios locales.

7 Mauzé, Marie / Harkin, Michael E. / Kan, Sergei (2004): Coming to shore: Northwest Coast ethnology, traditions, and visions. Lincoln: University of Nebraska Press, pp. 206-207.

8 Shannon, Anne P. (2012): Finding Japan: Early Canadian Encounters with Asia. Vancouver: Heritage, p.84. 
ses de otras muchas guías, muy prolijas en información dedicada al viajero, incluso el nivel de turistas en la zona, algo que mantendrían las propias publicaciones del gobierno japonés durante las décadas siguientes. También sitúa en Japón su única novela conocida, As the Hague Ordains (1907), un interesante reflejo de lo que ella vivió durante la Guerra Ruso-Japonesa, pero visto en este caso a través de los ojos de la mujer de un oficial ruso que se recuperaba en un hospital de Matsuyama.

Su visión de Japón no era idealizada o superficial, sino fundada en sus prolongadas estancias en el país. Como Chamberlain (1850-1935)9 ${ }^{9}$ temió que el Japón del período Edo fuera sepultado por la modernidad, asimilada de manera vertiginosa durante las eras Meiji (1868-1912) y Taishō (1912-1926). Es por ello que inició una campaña para fomentar el turismo para que se acudiera a ver lo que consideraba el alma inalterable ${ }^{10}$ de Japón, con las mínimas influencias a causa del rápido proceso de occidentalización en muchos campos.

Scidmore era consciente de que muchos turistas llegaban poco formados sobre la cultura de Japón, generalmente limitando su estancia a los puertos y grandes ciudades, perdiéndose experiencias únicas que habían estado al alcance de su mano ${ }^{11}$. Incluso los residentes extranjeros en el país durante años, no tenían ni un mínimo conocimiento sobre Japón ${ }^{12}$. Perseguía por lo tanto un doble fin: interesar al lector en su casa y formar al turista. Esa formación debía de ser continuada, antes, durante y después del viaje ${ }^{13}$, promoviendo además un turismo responsable y respetuoso ${ }^{14}$.

Este interés por el acercamiento armonioso entre culturas tampoco no se limitó a sus innumerables publicaciones y conferencias. Realizó numerosos préstamos de su extraordinaria colección particular ${ }^{15}$ a museos como el United States National Museum Washington, actual Smithsonian ${ }^{16}$. Pero su mayor contribución al intercambio cultural brotará ya tras su primer viaje a Japón en 1885. Scidmore quiso plantar cerezos japoneses en Wahington. aunque en ese primer momento, la idea no contó con los suficientes apoyos.

Finalmente, el veintisiete de marzo de 1912, tras veinticuatro años intentándolo, se inauguró en Washington, a orillas del Potomac, un paseo jalonado con 2.000 cerezos

9 Japonólogo y profesor de japonés en la Universidad de Tokio. A pesar de ello, la posición de Scidmore era bien clara, considerando como él que Japón era como una ostra, y que abrirla era matarla. Shannon, Anne P. (2012):

Finding Japan: Early Canadian Encounters with Asia. Vancouver: Heritage, 2012, p.84.

$10 \quad$ Ibid., p.84.

11 Scidmore, Eliza R. (1902): Jinrikisha Days in Japan. Coming to shore. Nueva York / Londres: Harper\&Brothers Publishers, pp. II.

12 Ibid., p. 365.

13 Holt-Atherton Special Collections [H-ASC], Washington D.C., 1891, 31/II/1891."Letter from Eliza Ruhamah Scidmore to [Louie Strentzel] Muir". En ocasiones continuaba formando personalmente a turistas que había conocido en sus viajes para que fueran verdaderos embajadores de la cultura del Japón que habían vivido.

14 Scidmore, Eliza R. (1902): Jinrikisha Days... op. cit, pp. 26, 31, 46, y 168. Por otro lado, reconocía que el turismo también hacía por mantener muchas tradiciones que se estaban perdiendo y posibilitar el acceso a lugares que antes eran exclusivos incluso entre los propios japoneses.

15 VV.AA (1925): Chinese \& Japanese porcelains \& potteries \& other Far Eastern objects of art : the collection of Miss Eliza Ruhamah Scidmore, Washington, D.C [...]. New York: The Anderson Galleries, pp. III-V y 24. Reputados expertos en cerámica como Stephen Wootton Bushell o Daijiro Ushikubo, reconocieron la gran calidad de su colección, subastada en 1925.

16 Anónimo (1925): “Throne Seat Brings \$350. Far Eastern Collection of Miss Eliza R. Scidmore Sold for \$6,480”. The New York Times, Nueva York, 11/1/1925. La colección completa alcanzó en la almoneda el valor de 6480 dólares. http:/query.nytimes.com/gst/abstract.html?res=9B07E7DB1038E233A25752C1A9679C946495D6CF\&legacy=true [Consulta: 27/5/2017] 
japoneses donados por la Municipalidad de Tokio ${ }^{17}$. Este acontecimiento, de enorme repercusión nacional e internacional ${ }^{18}$, afianzó en el imaginario colectivo la imagen de Japón con sus cerezos en flor ${ }^{19}$ como "...la cosa más bonita del mundo... ${ }^{20}$ ". Hoy en día esta contribución de Scidmore es símbolo de amistad entre Estados Unidos y Japón, conmemorado desde 1927 como el Festival Nacional de los Cerezos en Flor ${ }^{21}$.

\section{Scidmore La National Geographic}

El inicio de la relación de Scidmore con la National Geographic Society parte de su primera publicación independiente, Alaska, Its Southern Coast and the Sitkan Archipelago (1885). Sus artículos habían supuesto para muchos estadounidenses las primeras descripciones de esta región, lo que ayudó a aumentar el interés del gran público por la obra de Scidmore, motivando esa compilación de artículos y muchas ponencias por su parte ${ }^{22}$. Conscientes de este interés creciente, la revista publicó su conferencia Recent explorations in Alaska, durante la Conferencia Geográfica Internacional de Chicago de $1893^{23}$. Sin embargo, no sería hasta la publicación de Jinrikisa Days cuando el botánico David Fairchild (1869-1954) la invitara directamente a ser un miembro de la redacción, reconociéndola como autora de "inteligentes libros sobre Japón" ${ }^{24}$ lugar que él conocía bien. Desde entonces escribiría un total de dieciséis artículos, temas asiáticos en su mayoría, prolijamente ilustrados.

Con su incorporación a la directiva de la revista, fue la primera mujer ${ }^{25}$ en la junta de la recién creada National Geographic Society ${ }^{26}$. A pesar de los innumerables

17 Shurtleff, William / Aoyagi, Akiko (2012): Jokichi Takamine (1854-1922) and Caroline Hitch Takamine (18661954): Biography and bibliography. Lafayette: Soyinfo Center, pp. 241-242. Para ello fueron indispensables las figuras de dos insignes japoneses que se encontraban precisamente en Washington en 1909: Takamine Jokichi, un químico de reconocimiento internacional y Kokichi Mizuko, quienes junto a Hellen Taft, la Primera Dama, respaldaron el proyecto de Eliza hasta hacerlo también suyo. Desde 1935 se celebra en la capital americana el National Cherry Blossom Festival en honor a esta predisposición de buenas relaciones entre Estados Unidos y Japón, que se retomará en 1951 tras la Segunda Guerra Mundial.

18 Anonimo (1912): “Estados Unidos". La Lectura. Vol. 5, No 1, Mayo, Madrid, 1912, pp. 228-229. Incluso en España.

19 Véase: https://www.washingtonpost.com/local/cherry-blossoms-champion-eliza-scidmore-led-a-life-of-adventure/2012/02/22/gIQAAzHEAS_story.html [Consulta: 13/03/2012]. En España, la noticia también tuvo su repercusión. Véase: BNE [Biblioteca Nacional de España], Corresponsal en Ginebra, 1928, Nueva York, 4/ XI/1928. "MISS ELIZA SCIDMORE DIES IN GENEVA AT 72".

20 Vv.AA. (1997): "Her Blooming Great Idea". National Geographic. Vol. 191, No 4, Washington D.C., National Geographic Society, p. VII. Llevaba planteándose la idea desde 1885.

21 Véase: http://www.whitehousegifts.com/history-education/cherry-blossom-festival/ [Consulta: 1/1/2016]. Página oficial de la Casa Blanca.

22 Hemos de tener en cuenta que Alaska había sido adquirida a Rusia en 1867 y aún continuaba inexplorada en su mayor parte.

23 Scidmore, Eliza R. (1894): "Recent explorations in Alaska". The National Geographic Magazine, Vol. V, Enero. Washington D.C.: National Geographic Society, pp. 173-179.

24 Payne, Melvin R. (1988): “1988 The Trustees Who have Carried On The Tradition”. The National Geographic Magazine. Vol. 173, No 1, 20 Enero, Washington D.C.: National Geographic Society, p. 38

25 Hasta que Patterson, bibliotecaria y asistente de investigación se convirtió en la primera editora de la revista. En este sentido, Eliza R. Scidmore fue una excepción, ya que la otra mujer con algún cargo durante el período, Ida Minerva Tarbell (1901-1905), cumplió funciones simbólicas a pesar de su calidad como escritora e investigadora. Por ello se considera que hasta 1965 fue la única mujer con cargo directivo dentro de la revista. RothenBerg, Tamar Y. (2007): Presenting America's world: strategies of innocence in National Geographic Magazine, 1888-1945. Aldershot: Ashgate, p.138.

26 La noticia fue referida por todos los grandes periódicos de los EE.UU. La sociedad comenzó a publicar la revista en 1888, el mismo año de su fundación. LDN [Lincoln Daily News], La Redacción, 1892, Lincoln, 
viajes por las montañas de América del Norte y Asia, por lo general con estancias prolongadas en Japón, se encontraba establecida en Wahington D.C.. Inicialmente trabaja junto a dos editores asociados, en aquel momento no había ningún editor a tiempo completo en la publicación: W.J. McGee y A. W. Greely. En su correspondencia con los editores se deja ver su afilado humor en el trabajo, sus innumerables contactos, pero también su dominio sobre los protocolos legales de las embajadas, que empleaba para aconsejar a algunos de los más insignes exploradores del momento, como el escocés John Muir (1838-1914). Mantuvo esta posición entre 1896 a 1903, aunque continuó publicando artículos y fotografías hasta 1914.

Scidmore, con una larga trayectoria como articulista, viajera y geógrafa, se adaptó a los requisitos de la publicación. Inicialmente se trataba de una revista científica, pero con el peso de Gilvert H. Grosvenor (1875-1966), considerado el padre del actual fotoperiodismo fue dando un giro. Es por ello que las imágenes fueron cobrando cada vez más importancia, llegando a ser el principal atractivo de la publicación, resultando capital para el éxito de la revista hasta la actualidad. Pero al pasar a trabajar para la revista también cambiaba el tipo de lectores de Scidmore, al que ella comprendió perfectamente. Ya no eran turistas o residentes extranjeros temporales ${ }^{27}$, como en sus anteriores publicaciones, sino que Scidmore accedía ahora a los "viajeros de sillón". Con su característico estilo fresco, personal y rico en datos etnográficos, paisajísticos y anécdotas, no le fue difícil agradar a sus lectores. Todo ello sin sacrificar su rigor periodístico, como demostró cubriendo el tsunami de Sanriku de 1896.

\section{Fotografías}

A pesar de la importancia de Scidmore y del gran repertorio fotográfico que ha dejado, son pocos los estudios sobre su persona ${ }^{28}$, menos aún sobre su trabajo como fotógrafa. Ya en 1885 mostró interés por la fotografía, de una manera amateur, para documentar las anotaciones que iba realizando ${ }^{29}$. Este proceso, unido a la adquisición de fotografías fue el germen de un gran corpus documental. A la hora de escribir los libros, muchas de estas fotografías le sirvieron de inspiración, o directamente como ejemplo, para los ilustradores.

En la primera década de la National Geographic Magazine, bajo la nueva dirección, las fotografías ya se perfilaban como uno de los elementos indispensable en la transformación de revista científica a una publicación más didáctica y comercial. Dada la enorme competitividad aglutinó a los mejores fotógrafos de su tiempo, iniciando además una férrea defensa de los derechos de reproducción ${ }^{30}$.

Nebrasca, 22/III/1892, p.3, TNT [The National Tribune], La Redacción, 1892, Washington, 19/III/1892, p.5, entre otros.

27 Scidmore, Eliza R. (1902): Jinrikisha Days in Japan. Coming to shore. Nueva York / Londres: Harper\&Brothers Publishers, pp. I.

28 Actualmente, sus dos mayores investigadores son Daniel Howard Sidmore y Diana Parsell, aunque siguen pendientes publicaciones de carácter global sobre la figura de Eliza. La mayor parte de su correspondencia y archivos fueron quemados según su testamento, lo que dificulta enormemente cualquier estudio.

29 Parte de esta documentación se encuentra en el Smithsonian, dentro del departamento National Anthropological Archives, pendiente de estudio y atribución.

30 Scidmore, Eliza R. (1907): "Women and children of the East". The National Geographic Magazine. Vol. XVIII, $N^{o}$ 4, April. Washington D.C.: National Geographic Society, p. 248. En el encabezamiento de su artículo, puede leerse: "All these illustrations are copyrighted by the National Geographic Society, 1907, and their republication without permission is prohibited". 
Las primeras fotografías de Scidmore aparecieron publicadas en el artículo Women and children of the East (1907). Se trataba de una compilación de fotografías sobre esta materia tomadas en sus viajes, dando una importancia secundaria al texto. Por lo general se trata de escenas cotidianas muy variadas, con una potente vertiente antropológica y estética ${ }^{31}$. La revista anunciaba en su portada esta colección de imágenes, en detrimento de artículos de los fundadores de la sociedad ${ }^{32}$. La causa principal de esta posición tan meritoria era la admiración de Grosnevor por las fotografías Scidmore, reconociendo que ella "se fijaba en la vida y acciones de las personas de una manera que un hombre no sería capaz" ${ }^{33}$. Éstos eran precisamente los principios por los cuales la revista se comenzó a interesar por culturas que les resultaban foráneas: "conociendo otras culturas, acercándose a la esencia de la naturaleza humana, contribuyendo al desarrollo de cualquier persona" 34 .

La obra de Scidmore entra por ello en estrecha relación con la antropología, especialmente las fotografías dedicadas a sus propias notas de estudio. El nivel de detalle es absoluto, reflejando la inigualable capacidad analítica de la escritora. Un ejemplo es que, cuando hablaba de obi (cinturones de quimono), adjuntaba un pormenorizado estudio del origen de sus manufacturas y una serie de imágenes para captar las diferencias en sus texturas ${ }^{35}$, dando también a conocer al lector que muchos otros detalles quedaban sin aludir.

La otra tipología fotográfica que trató es prácticamente el género opuesto. Se trataba de fotografías de estudio, o muy preparadas, de composición cuidada, con posados y decorados que pretenden contar una historia. En cierta manera deja entrever su propia imagen del Japón más tradicional, donde "las casas parecen de juguete, y sus habitantes, muñecos"36. Las composiciones son estudiadas al milímetro cuando trata de narrar una escena mucho más compleja e interrelacionada con su entorno, como un gran fuera de campo cinematográfico. Todo ello en la línea de la época más comercial constructivista y orientalista del Barón Raimund von Stillfried, y mucho más romántica. La intención era atraer suscriptores con imágenes llamativas [figs. 1 y 2] según ella misma comenta a Grosnevor ${ }^{37}$. Sabemos que incluso se implicó personalmente en el proceso de coloreado de las imágenes ${ }^{38}$. Scidmore; por lo tanto, aun siendo plenamente consciente de la construcción que hace del Japón tradicional, recreó específicamente para estas fotografías un auténtico japonismo del que no era partícipe.

Scidmore se vio atraída por el empleo del color en la fotografía, como una manera de acercarse aún más a la realidad y añadir expresividad a las imágenes. De hecho, para una de esas publicaciones realizó una serie de encargos. Por aquel entonces las fotografías debían de colorearse a mano una a una, algo que en Japón, gracias a las albúminas vendidas a los extranjeros como souvenirs, estaba plenamente extendido. Uno de estos lotes, de 1912, estaba compuesto por "treinta y una imágenes de muje-

31 Ibidem. Esta publicación de 1907 la convierte de facto en la primera fotógrafa que publica para la revista, no en 1914, como se venía manteniendo hasta ahora.

32 Scidmore, Eliza R. (1907): "Women and children..., op. cit., p. (Cubierta).

33 Véase: http://proof.nationalgeographic.com/2013/10/09/women-of-vision-the-pioneers/ [9/10/2013]

34 Ibid., p. 248.

35 Scidmore, Eliza R. (1902): Jinrikisha Days ..., op. cit., pp. 262-265.

36 "The houses seem toys, their inhabitants dolls". Shannon, Anne P. (2012): Finding Japan: Early Canadian Encounters with Asia. Vancouver: Heritage, p. 83.

37 McCArry, Charles (1988): "Three Men Who Made the Magazine". The National Geographic Magazine, Vol. 174, N 3, Washington D.C., National Geographic Society, 1988, p. 297.

38 Ibidem. 
res y niños... muy coloreadas" ${ }^{\prime 39}$, que sólo se conservan parcialmente en los fondos de la revista. Hasta 1930 la revista no se imprimió en color de manera más sistemática, limitándose el color a publicaciones especiales.

Fig. 1. Eliza Ruhamah Scidmore, Niña asomándose tras el biombo, c.1912, fotografía en blanco y negro coloreada a mano, $142 \times 98$ mm., Muséu del Pueblu d'Asturies.

Eliza realizó muchas fotografías donde lo mono o kawaii eran el tema central.
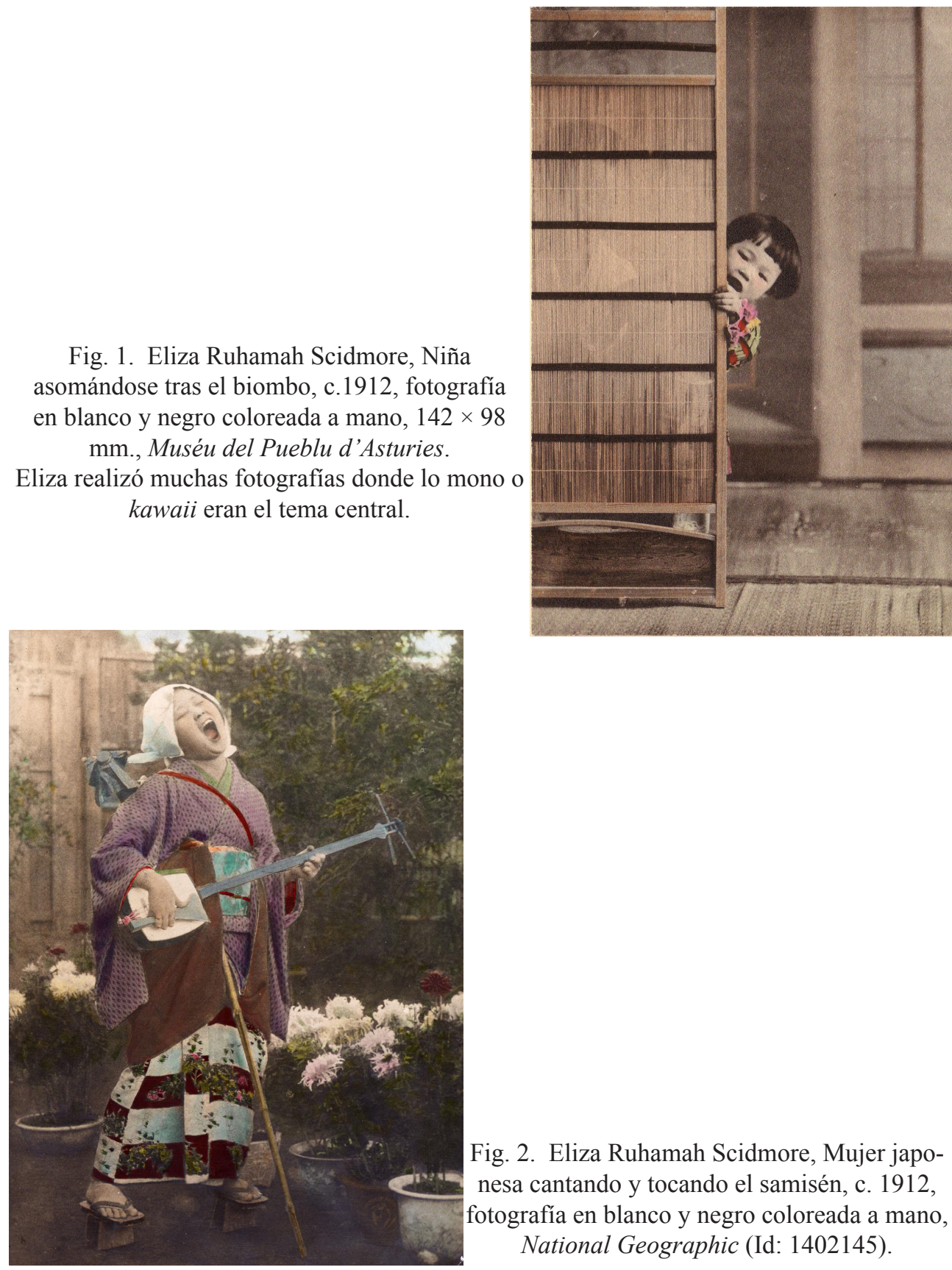

Fig. 2. Eliza Ruhamah Scidmore, Mujer japonesa cantando y tocando el samisén, c. 1912, fotografía en blanco y negro coloreada a mano, National Geographic (Id: 1402145).

39 Ibid., p. 297. Especial cien años de la revista. 


\subsection{Nuevas fotografías de Eliza Scidmore}

A pesar de la dilatada experiencia de la corresponsal trabajando con las fotografías, la difusión de las mismas fue muy limitada. Sólo un pequeño número de las mismas se publicaron en sus libros o en la revista, mientras que otras pasaron a los fondos de la National Geographic Society ${ }^{40}$. Sin embargo recientemente han aparecido en el Muséu del Pueblu d'Asturies, en Gijón, un total de dieciocho, junto a cinco posibles atribuciones, con una conservación y calidad excepcionales.

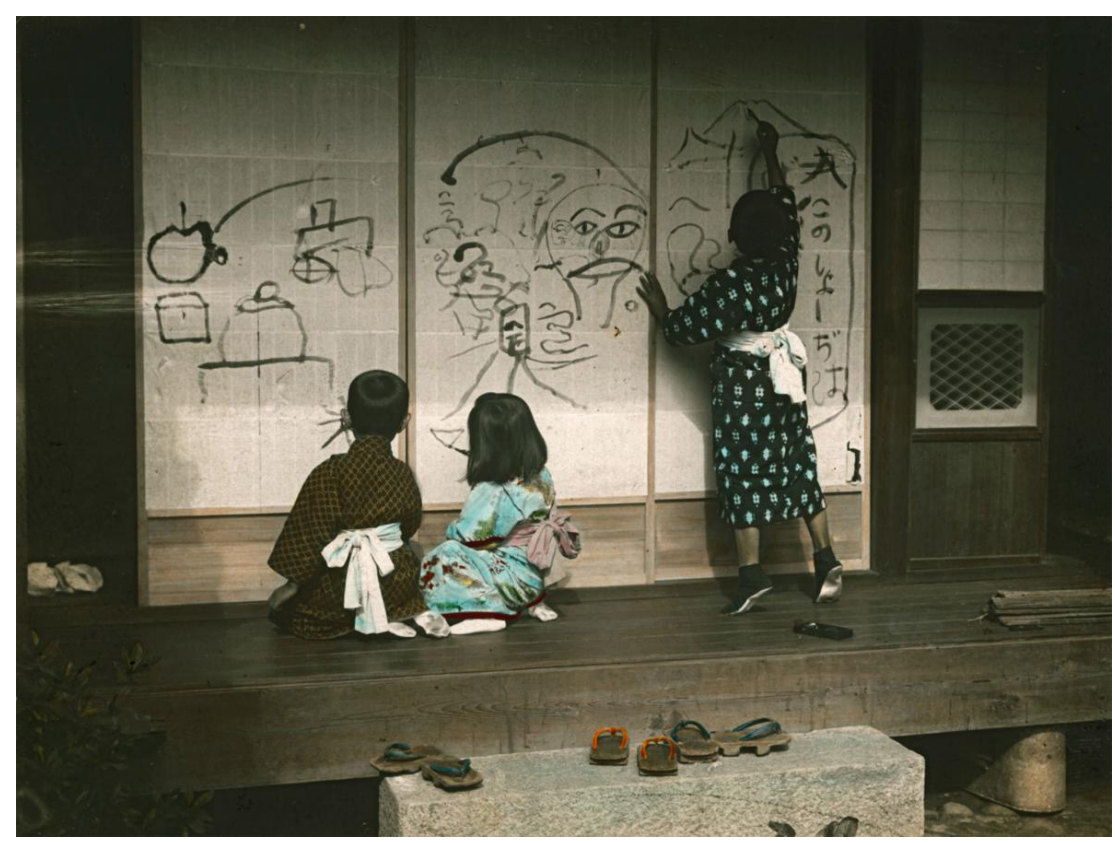

Fig. 3. Eliza Ruhamah Scidmore, niños pintando el papel shōji antes de retirarlo, c.1912, fotografía en blanco y negro coloreada a mano, National Geographic (Id: 603044).

Estas fotografías formaron parte de la colección personal del avilesino Jesús Teodoro Galé Pérez (1877-1929). Esta colección contaba con más de ochocientas fotografías de Asia, conformando a día de hoy uno de los mayores archivos de su categoría en España ${ }^{41}$. Jesús viajó a través de toda Asia al menos en veinte ocasiones, como representante de diversas casas comerciales de farmacéuticas y perfumistas parisinos. Aprovechando dicha ruta, amplió su colección personal de objetos de arte asiático, hasta el punto que se convirtió en un marchante de arte asiático de primera línea. Llegó a poseer una buena colección de albúminas japonesas coloreadas. Pese a que Jesús Teodoro, pasó una temporada como representante de diversas firmas en

$40 \quad$ Scidmore, Eliza R. (1907): "Women and children..., op. cit., p. 248.

41 Véase: https:/www.gijon.es/multimedia_objects/download?object_type=document\&object_id=147767 [Consulta: 27/5/2017] Este catálogo se corresponde con un pequeño resumen, centrado en Japón, de la colección fotográfica de la Familia Galé en el Museo. La colección cuenta en total con cerca de un millar de fotografías realizadas por Juan Galé en 1927 en su viaje por Asia. 
Washington y estuvo presente todos los años en Japón desde 1900 hasta 1928, nada parece indicar que hubiera conocido a la fotógrafa.

Autentificar la autoría y datar dichas fotografías resulta con suerte una tarea ardua en el mejor de los casos e imposible en muchos de ellos. Tras la apertura de Japón a Occidente en 1854 se asentaron en Japón varios fotógrafos occidentales, entre los que destacaron Felice Beato y el Baron Raimund von Stillfried. Los aprendices japoneses de los mismos heredaron sus talleres, y con ellos, la mayoría de negativos que se conservaban. Tras un par de generaciones, resultaba casi imposible aseverar la autoría de las mismas, llegando incluso a positivar las mismas fotografías durante décadas.

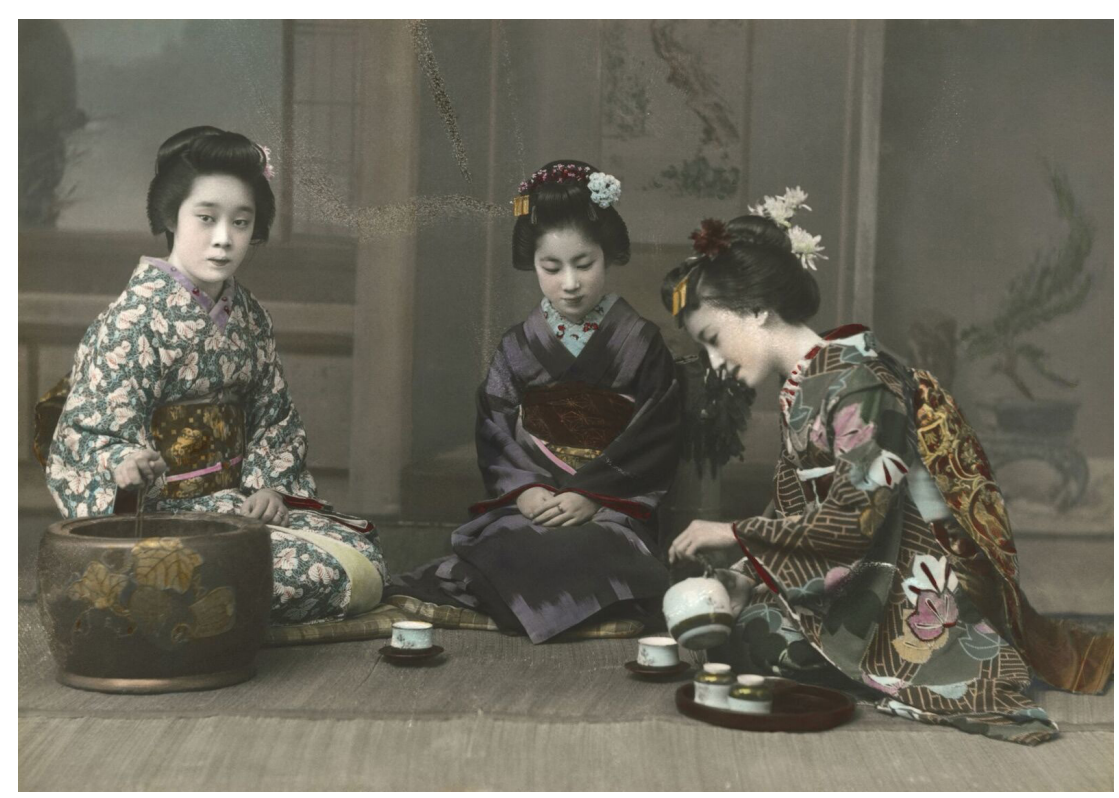

Fig. 4. Eliza Ruhamah Scidmore, Maiko con ramas de cerezo, c.1912, fotografía en blanco y negro coloreada a mano, $190 \times 240 \mathrm{~mm}$., Muséu del Pueblu d'Asturies (R-40627). De nuevo, las mismas modelos se muestran en diferentes poses de las registradas en el fondo del National Geographic.

En un primer momento las fotografías de Scidmore en el Muséu del Pueblu d'Asturies fueron atribuidas a Takagi. Co (o Tamamura), una compañía japonesa con gran tradición de fotógrafos fundada por Takagi Teijiro ${ }^{42}$, ya que en las cajas había aparecido un sobre de dicha compañía. No obstante, no aparecían copias similares en ninguna publicación, archivo o museo. Esto, unido a la gran calidad de

42 Bennet, Terry (2006): Photography in Japan. 1853-1912. Tokyo / Rutland, Vt: Tuttle, p. 294. Relacionado a su vez con el famoso taller de Tamamura Kozaburō. 
las mismas, tanto en pintura como en impresión y materiales ${ }^{43}$, indicaba que no se trataba de meras fotografías para turistas. Esto se confirmó cuando, pudimos acceder al archivo completo de la National Geographic Society, donde se atesoraban varias fotografías inéditas de la autora que se correspondían con las del museo asturiano ${ }^{44}$ : Maiko con ramas de cerezo (R-40627), maiko con crisantemos (R-40619) y niña con gallina (R-40620).

Las fotografías de Scidmore preservadas en Gijón se centran en las dos temáticas ya mencionadas: maiko y niños en actitudes kawaii. [fig. 3] Sin embargo, al ser dieciséis las fotografías podemos realizar nuevas aportaciones con respecto a la obra de Scidmore.

En primer lugar, todo parece indicar que los negativos de Scidmore terminaron en manos de Futaba Photo. Co., antes o después de asentarse en Kobe, y de ellos a sus sucesores Takagi. $\mathrm{Co}^{45}$., sin descartar que entre medias no pasaran por las manos de otros estudios. Estos siguieron vendiendo las fotografías de Scidmore como propias, tras haber colaborado en el encargo de la autora. Incluso es posible que originariamente pertenecieran a otro fotógrafo que desconocemos y que se vendieran a Futaba. Lo que es seguro es que los negativos pasaron a comercializarse de dos

Hay indicios que parecen indicar que el taller que realizó las fotografías de Washington y de Gijón fuera el mismo. El más evidente es la calidad de las policromías que resultan idénticas, como en el caso de ID 708179 (National Geographic Society Archive) y R-40627 (Muséu del Pueblu d'Asturies). Como es comprensible, cuando un negativo pasaba de un taller a otro, no se tomaba especial atención en seguir aplicando los mismos colores para cada elemento, en ocasiones, ni siquiera dentro de los mismos talleres. Sin embargo, en estos ejemplos se corresponden incluso las policromías de los quimonos, algo nada habitual. Esto podría indicar que algunas de las imágenes fueron impresas y pintadas de manera prácticamente simultáneas a las que Scidmore envió a la revista, correspondiéndose con las que supervisó personalmente ${ }^{46}$.

Por otro lado, nos encontramos con las mismas tres maiko en muchas de las fotografías $^{47}$. No sólo eso, sino que además visten los mismos kimonos, lo que reforzaría la idea de haberse realizado en la misma sesión de fotografías, bajo la dirección de Scidmore. En cuanto a la composición, se trata siembre de varias maiko en diferentes poses, pero sin realizar ninguna actividad particular. Los elementos naturales como punto de unión, especialmente crisantemos y cerezos [fig. 4]. El estilo se diferencia de sus coetáneos en una visión más preciosista y cercana. Esto es propio de las fotografías previas de Scidmore, especialmente aquellas con más carácter antropológico o de estudio ${ }^{48}$. A este respecto hay un claro interés en las composiciones de cara a mostrar los bordados de los kimonos ${ }^{49}$, pensando en lo llamativo de las imágenes una vez se coloreen [fig. 5].

43 Sobre todo, el que en lugar de la técnica de la albúmina se empleara gelatino-bromuro coloreado, muy caro y complicado.

44 Mi más sincero agradecimiento a Gina Martin, del departamento de la National Geographic Creative por toda la ayuda prestada y concederme el acceso a los archivos de Washington.

45 Sobre sin catalogar. Muséu del Pueblu d'Asturies.

46 McCARry, Charles (1988): "Three Men ..., op. cit., p. 297.

47 Las mismas modelos que aparecen en la fotografía Id: 708179, aparecen en el archivo de Gijón en las en los registros R-40617, R-40618, R-40619 o R-40627.

48 Véase: http://proof.nationalgeographic.com/2013/10/09/women-of-vision-the-pioneers/ [Consulta: 9/10/2013]

$49 \quad$ R-40617, R-40618, R-40619. 
Las fotografías de estas maiko presentan unas características técnicas bastante homogéneas. Su tamaño, 21,5 × 29,5 cms. se mantiene de manera uniforme. Presentan un coloreado especialmente preciosista, con papel con gramaje de alta calidad y sin albúmina. Los colores son muy homogéneos y precisos, algo nada habitual, sobre todo en un período tan tardío. De hecho, las veladuras son muy ligeras para respetar los degradados de grises, como es el caso de la fotografía maiko con ramas de cerezos. En esta puede apreciarse tanto el cuidado en la decoración de los kimonos como las sutiles carnaciones para resaltar las figuras sobre el fondo uniforme.

Únicamente una fotografía de las tres citadas maiko no se corresponde con esta tipología (R-40619), tratándose de un fototipo de menor tamaño $(14,2 \times 9,8 \mathrm{cms}$.) pegado sobre lienzo de cartón. Pese a estar igualmente coloreada a mano, la calidad y el detalle son claramente inferiores, no correspondiéndose además con los de las fotografías supervisadas por Scidmore. Sin lugar a dudas se tratan de reimpresiones de Takagi Co., para un mercado más amplio, propiamente souvenirs. Se da por lo tanto una situación de interculturalidad, en la que la intención original de Scidmore, atraer al público hacia lo que quedaba del Japón tradicional, pasaba a reforzar el japonismo.

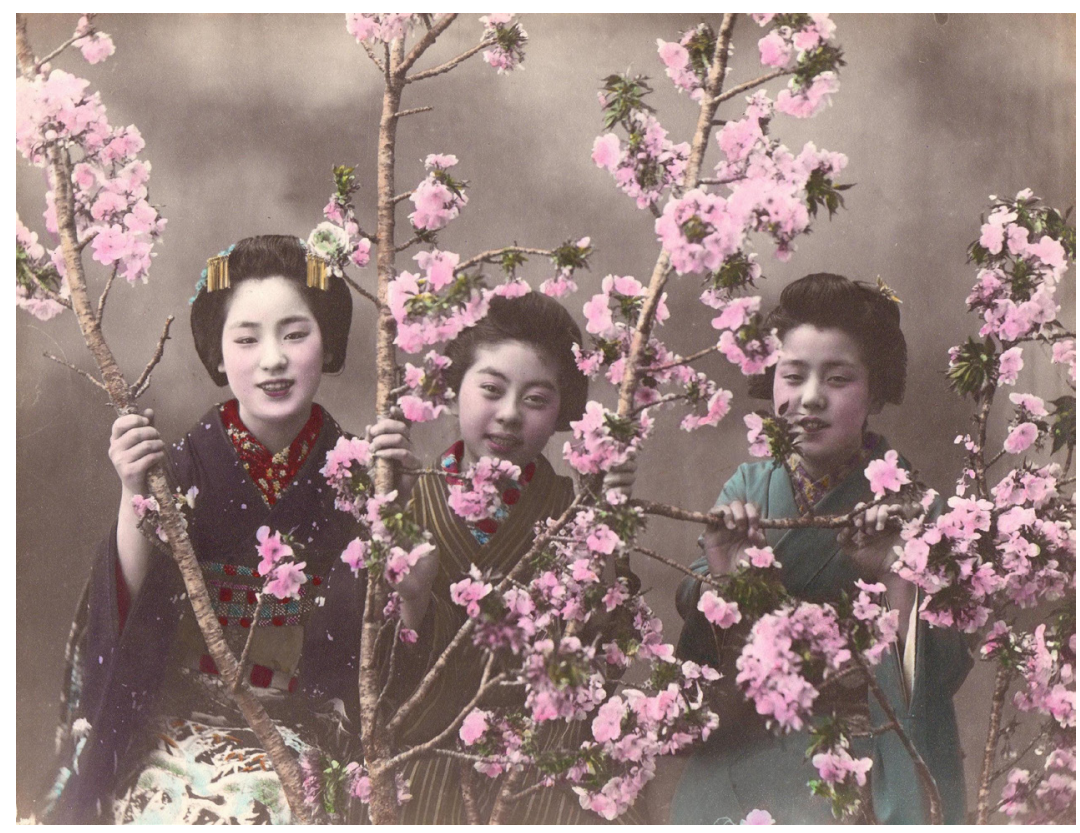

Fig. 5. Eliza Ruhamah Scidmore, Maiko durante una ceremonia del té, c.1912, fotografía en blanco y negro coloreada a mano, National Geographic (Id: 708179). Las mismas modelos de la imagen aparecen en varias fotografías del Muséu del Pueblu d'Asturies.

La segunda temática de las fotografías en el Muséu del Pueblu d'Asturies es la que halagaban los redactores de la revista ${ }^{50} \mathrm{y}$ en la que más se diferenciaba la fotografía de Scidmore: el de carácter documental, íntimo o etnográfico. En ellas se

50 Véase: http://proof.nationalgeographic.com/2013/10/09/women-of-vision-the-pioneers/ [09-10-2013] 
desprende un sentimiento de pureza y alegría, poco habitual en las fotografías destinadas a su venta y difusión en Occidente ${ }^{51}$. La fotografía de niños, más aún los bebés, había sido motivo de atención por parte de los fotógrafos japoneses, incluso por los estudios occidentales de la primera mitad del siglo XIX. No obstante, con Scidmore, esta característica no llega a su máxima expresión, en la que el niño pasa a ser el protagonista absoluto de la imagen. Se establece un claro paralelismo con las fotografías de la vida cotidiana de los niños que la fotógrafa realizara con anterioridad en Japón, China, la India y Java. En las fotografías del museo asturiano se presenta una visión más rural (R-40620, R-40698), además de mucho más relacionada con el mundo del juego con el espectador (R-40696- R-40697) donde los niños aparecen escondiéndose, interpelando directamente al fotógrafo.

No obstante, como sucedía con las maiko, se trata de escenas construidas, a pesar de tratarse de una temática diferente. Incluso realizadas en estudio (R-40696, R-40697), aunque buscando otorgarles un carácter anecdótico y jovial, plenamente logrado por las actitudes de sus protagonistas. Se trata por lo tanto de una serie de construcciones de Japón de cara a Occidente ${ }^{52}$, algo que venía siendo habitual en la fotografía japonesa de exportación ${ }^{53}$, pero excepcional en la obra de Scidmore hasta la fecha.

De nuevo, como en el caso de las maiko lo que estas imágenes pierden en verosimilitud, lo ganan en estética. Pero en contraste con éstas, sin alejarse completamente de las técnicas empleadas por Scidmore para sus fotografías de documentación. Ejemplo de ello es, no sólo la cercanía a las figuras, si no, mucho más evidente, la altura del objetivo, a la altura de los niños. Sin embargo, en estos casos, además de por sus protagonistas, los ambientes son más reales y acercan estas imágenes preparadas mucho más hacia la idea del Japón auténtico, tradicional y atractivo que Scidmore quería captar.

\section{Conclusiones}

Además de ser el primer estudio sobre la fotografía asiática de Scidmore, las nuevas fotografías suponen una aportación ineludible tanto para el estudio de la obra gráfica y escrita de Eliza Ruhamah Scidmore como para la revista National Geographic. Todo ello con el telón de fondo de los archivos y museos españoles que se están revelando como una fuente constante de sorpresas para los estudios del arte japonés y sus influencias.

La obra gráfica de Scidmore supuso un punto trascendental para la historia de la National Geographic Society y un nuevo avance en el estudio de la difusión de la imagen de Japón en Occidente. Cientos de miles de lectores en todo el mundo tuvieron acceso a estas imágenes, siendo uno de los japonismos construidos por Occidente con más difusión, además de uno de los más tardíos, por no hablar de la difusión confirmada de sus fotografías a través de reimpresiones de Takagi. Co, convirtiendo las imágenes para la National Geographic en souvenirs y no al contrario.

51 Bennet, Terry: Photography in Japan. 1853-1912. Tokyo Rutland, Vt: Tuttle, 2006, pp. 230-231.

52 TUCKer, Anne, / IIzAwa, Kotaro / Kinoshita, Naoyuki (2003): The history of Japanese photography. New Haven: Yale University Press / Museum of Fine Arts, Houston, p. 157.

53 ODo, David (2015): The journey of " a good type": from artistry to ethnography in early Japanese photographs. Cambridge, Massachusetts: Peabody Museum Press, Hardvard Univesity, p. 50. 
Con la localización de algunas de las "treinta y un imágenes de mujeres y niños... muy coloreada" ${ }^{54}$ perdidas que realizó para la revista en 1912, se confirma la transformación de la fotografía de Scidmore de documental a publicitaria, bajo las necesidades del The National Geographic Magazine, con todo lo que esto implica. Sin embargo, no perdió completamente ni las referencias etnográficas, ni su visión analítica o su interés por la figura de la mujer y de la infancia. El resultado fue la creación de un japonismo híbrido y muy particular, con el objetivo concreto de aumentar las ventas de National Geographic, evidenciando la faceta más comercial de alguien que llevaba toda su carrera tratando de fomentar los viajes a un Japón tradicional que conocía y admiraba, antes de que éste extinguiera definitivamente. 